\title{
Effect of intrathecal nimodipine on spinal cord blood flow and evoked potentials in the normal or injured cord
}

\author{
Hiroyuki Imamura and Charles H Tator \\ Canadian Paraplegic Association Spinal Cord Research Laboratory, Division of Neurosurgery and Playfair \\ Neuroscience Unit, The Toronto Hospital, Western Division, and University of Toronto, Toronto, Ontario, Canada
}

\begin{abstract}
A method was developed for administering intrathecal pharmacotherapy in a rat model of spinal cord injury. The effects of intrathecal administration of nimodipine on spinal cord blood flow (SCBF) and evoked potentials (EPs) were measured in the normal and injured spinal cord. It had previously been shown that systemic nimodipine caused severe hypotension after spinal cord injury. After baseline SCBF and EPs, 15 uninjured rats were blindly allocated to one of three groups: one placebo group $(n=5)$; and two groups with intrathecal nimodipine, $0.05 \mathrm{mg} / \mathrm{kg}(n=5)$, or $0.2 \mathrm{mg} / \mathrm{kg}(n=5)$. Ten other rats received a $35 \mathrm{~g}$ acute clip compression injury of the spinal cord for 1 minute and, were allocated to one of two groups: placebo $(n=5)$; and intrathecal nimodipine $0.05 \mathrm{mg} / \mathrm{kg}(n=5)$ given $60 \mathrm{~min}$ after injury. In the uninjured groups, neither 0.05 nor $0.2 \mathrm{mg} / \mathrm{kg}$ of nimodipine increased SCBF during, or $30 \mathrm{~min}$ after, intrathecal infusion. However, the mean arterial blood pressure (MABP) decreased significantly to $69.73 .1 \%$ after the infusion of $0.2 \mathrm{mg} / \mathrm{kg}$ nimodipine and did not recover by $98 \mathrm{~min}$. In all three groups of uninjured rats, the amplitude of the cerebellar EP was decreased 30 min after infusion. After spinal cord injury, there were significant decreases in MABP, SCBF and EP amplitude in both placebo and treatment groups, but there was no therapeutic benefit from nimodipine. Thus, intrathecal infusion of nimodipine did not prevent the hypotension encountered with systemic administration and exerted no beneficial effect on SCBF or EPs after acute spinal cord injury.
\end{abstract}

Keywords: evoked potentials; intrathecal injection; nimodipine; spinal cord blood flow; spinal cord injury

\section{Introduction}

It has been hypothesized that there are two mechanisms of damage to the spinal cord after acute spinal cord injury: the primary mechanical injury, and a secondary injury due to one or more additional damaging processes initiated by the primary injury. ${ }^{1-3}$ Several attempts have been made to treat acute cord trauma by preventing or attenuating the secondary injury. For example, calcium channel blockers have been studied in experimental models of spinal cord ischemia or trauma ${ }^{4-16}$ with variable effects on performance, morphology, and spinal cord blood flow (SCBF). Our laboratory selected nimodipine for use in spinal cord injury ${ }^{7,9,10}$ because its high lipid solubility allows good penetration into the central nervous system. However, due to the systemic hypotension caused by the combination of cord trauma and nimodipine, it was necessary to provide treatment to counteract the hypotension in order to maintain post-traumatic mean arterial blood pressure (MABP). ${ }^{7,9,10}$ In our opinion, failure to counteract

Correspondence: $\mathrm{CH}$ Tator post-traumatic hypotension was an important reason for the lack of improvement seen with nimodipine in some studies of spinal cord injury. $5,6,8,11,13,17$ In our laboratory, when adjuvant therapy was given to counteract post-traumatic hypotension, nimodipine produced an improvement in SCBF. ${ }^{7,9,10}$ For example, when adrenalin was used to maintain the posttraumatic MABP at a normal level, there was $60 \%$ recovery of SCBF with nimodipine.9,10 However, adrenalin is a vasoconstrictor, and there were some reports that it might worsen neuronal damage after spinal cord injury. ${ }^{18,19}$ Nimodipine $0.02 \mathrm{mg} / \mathrm{kg}$ combined with dextran improved post-traumatic MABP, SCBF and axonal function, ${ }^{7}$ but after cessation of this therapy SCBF decreased again and axonal function declined. However, dextran cannot be used for long term administration because it causes allergic reactions in Wistar rats. ${ }^{15}$ When albumin was used as an adjuvant, post-traumatic MABP was maintained, but there was no recovery of post-traumatic SCBF or axonal function. ${ }^{15}$

Although intrathecal pharmacotherapy has been used effectively for a variety of central nervous system 
diseases such as chronic pain and spasticity, ${ }^{20-22}$ this route of drug administration has not yet been reported for the treatment of acute spinal cord injury. Intrathecal administration of nimodipine would permit the drug to act directly on the adventitial surface of the larger vessels and, after it diffuses into the spinal cord, to also act directly on the larger intramedullary vessels and capillary bed in the spinal cord. ${ }^{21}$ Another potential advantage is the avoidance or minimization of significant systemic side effects such as hypotension which occur after systemic administration.

The purpose of the present study was to determine whether intrathecal nimodipine would alter MABP, SCBF and evoked potentials in normal and injured rats.

\section{Materials and methods}

Twenty-five male Wistar rats weighing 351-497 g were anesthetized by intraperitoneal injection of a-chloralose $(75 \mathrm{mg} / \mathrm{kg})$ and urethane $(525 \mathrm{mg} / \mathrm{kg})$. The right femoral vein was used for administration of saline containing $5 \%$ albumin and $2 \%$ sodium bicarbonate at a rate of $7.0 \mathrm{ml} / \mathrm{kg}$ /hour through a Harvard syringe infusion pump (Model 2620 Harvard Apparatus, South Natick, MA, USA), and the right femoral artery was used for monitoring MABP. Rectal temperature was maintained at $36-38^{\circ}$ EC using a heating blanket and a heating lamp. After a tracheostomy was performed, the rats were placed in a stereotactic frame, and burr holes were placed over the right sensorimotor cortex ( $1 \mathrm{~mm}$ posterior and $2 \mathrm{~mm}$ lateral to the bregma) and left cerebellar hemisphere $(1 \mathrm{~mm}$ posterior and $2 \mathrm{~mm}$ lateral to the inion). The left sciatic nerve was exposed and a laminectomy was made from $\mathrm{C} 1$ to $\mathrm{T} 1$. A silastic tube of inner diameter $0.3 \mathrm{~mm}$ and outer diameter $0.625 \mathrm{~mm}$ was inserted into the dorsal subarachnoid space via the atlantooccipital membrane until its tip reached the dorsal surface of $\mathrm{C} 6$. The opening in the atlantooccipital membrane was sealed by a small piece of gauze and cyanoacrylate glue. The animal was paralyzed with pancuronium bromide $(0.7 \mathrm{mg}$ as an initial dose, then $1 \mathrm{mg} / \mathrm{kg}$ every $30 \mathrm{~min}$ ) and ventilated with a 2:1 mixture of $\mathrm{O}_{2}$ and $\mathrm{NO}_{2}$ with a Harvard rodent ventilator (model 683). Arterial blood gases were kept in the physiological range $\left(\mathrm{PaO}_{2}>\right.$ $100 \mathrm{mmHg}$ : $\mathrm{PaCO}_{2}$ at $35-45 \mathrm{mmHg} ; \mathrm{pH}$ at $7.35-$ $7.45)$ by adjustments in ventilation or small amounts $(0.2-0.5 \mathrm{ml})$ of sodium bicarbonate $(1 \mathrm{mEq} / \mathrm{ml})$.

\section{SCBF measurement}

Under microscopy two holes were made in the dura $0.5 \mathrm{~mm}$ lateral to the midline at $\mathrm{T} 1$ by piercing the dura with a 3-0 Dexon II surgical suture needle (DAVIS + GECK, Inc., American Cyanamid Company, Manati, PR 00701, USA). SCBF was measured by the hydrogen clearance method described before. ${ }^{23}$ Briefly, with a micromanipulator, two platinum-iridium microelectrodes with a $10 \mathrm{~mm}$ tip diameter were inserted sterotactically under the microscope through the dural openings into the dorsal column of the cord to a depth of $500 \mathrm{~mm}$. An $\mathrm{Ag}-\mathrm{AgCl}$ disc electrode was placed subcutaneously as a reference. Linear regression was used on-line to compare the presaturation polarographic baseline level with the desaturation baseline level. The initial slope index method was used to calculate the SCBF from the logarithmically transformed desaturation curves. SCBF was measured before infusion, during infusion and after infusion of the placebo or nimodipine.

\section{Recording of evoked potentials}

Evoked potentials (EPs) were recorded using a signal averager (Cadwell 8400, Kennewick, Washington). The left sciatic nerve was stimulated with a bipolar electrode using cathodal stimulation of $5 \mathrm{~mA}$, $4.05 \mathrm{~Hz}$ and duration of $50 \mathrm{msec}$. Somatosensory evoked potentials (SSEPs) were recorded from a platinum ball electrode, $0.8 \mathrm{~mm}$ in diameter, placed epidurally through the right burr hole over the right sensorimotor cortex, and cerebellar evoked potentials $(\mathrm{CEPs})^{24}$ were recorded from an electrode placed epidurally through the left occipital burr hole over the left paramedian lobule of the cerebellar hemisphere. An $\mathrm{Ag}-\mathrm{AgCl}$ disc electrode, $8 \mathrm{~mm}$ in diameter, placed between the hard palate and the tongue acted as a reference. An EEG needle electrode was inserted subcutaneously between the stimulating and recording electrodes and was connected to a floating ground. A total of 200 SSEP and CEP responses were recorded at a bandwidth of $30-3000 \mathrm{~Hz}$, averaged, and replicated. Representative waveforms of the SSEP and CEP are shown in Figure 1. The latency and amplitude of P13 and N18 of the SSEP and N9 and P14 of the CEP were measured. EPs were recorded immediately after the measurement of SCBF at each time interval.

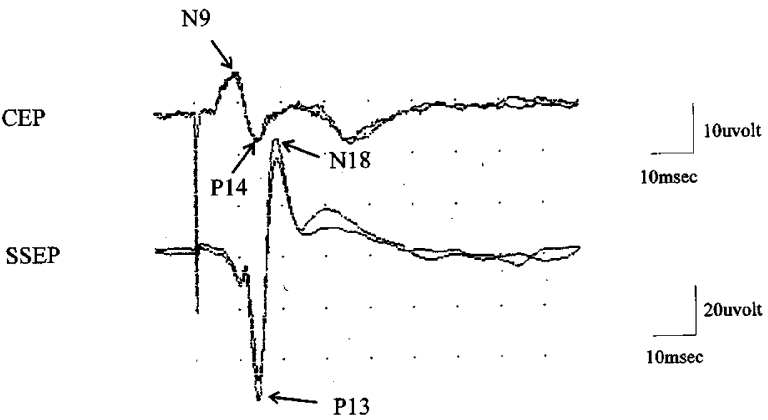

Figure 1 Representative waveforms of evoked potentials. Both types of EPs were recorded simultaneously, and replicated for each record. Top: Cerebellar evoked potentials (CEPs) were recorded from the left paramedian lobule by stimulating the left sciatic nerve. Bottom: Somatosensory evoked potentials (SSEPs) were recorded from the right sensory motor cortex by stimulating the left sciatic nerve. The SSEP consisted of three negative and three positive peaks 


\section{Experimental protocol}

The experimental protocol is schematically shown in Figure 2. Following the baseline (preinfusion) recordings of SCBF and EPs, normal rats were randomly and blindly assigned to one of three groups (five animals in each): placebo; nimodipine $0.05 \mathrm{mg} / \mathrm{kg}$; and nimodipine $0.2 \mathrm{mg} / \mathrm{kg}$. The placebo was the diluent for nimodipine supplied by Miles Laboratories consisting of a solution of polyethylene glycol-400 $(170 \mathrm{mg} / \mathrm{mL})$, ethanol $(200 \mathrm{mg} / \mathrm{mL})$, sodium citrate $(2 \mathrm{mg} / \mathrm{mL})$ and anhydrous citric acid $(0.3 \mathrm{mg} / \mathrm{mL})$. Placebo or nimodipine was infused into the subarachnoid space with a Harvard infusion pump (Model 901 Harvard Apparatus, South Natick, MA, USA) for $30 \mathrm{~min}$ in $0.5 \mathrm{ml}$ diluent beginning $30 \mathrm{~min}$ after the baseline SCBF was obtained. The infusion syringes were protected from light with aluminium foil, and a sodium vapour lamp was used during dilution of the drug due to the photosensitivity of nimodipine to normal light.

\section{Spinal cord injury}

In another 10 rats after baseline SCBF and EPs were recorded, an acute cord clip compression injury was made at $\mathrm{T} 1$ with a $35 \mathrm{~g}$ clip for 1 min (Figure 3 ). This injury was produced by placing a modified KerrLougheed aneurysm clip around the cord extradurally. ${ }^{25}$ The modified clip has curved blades to facilitate extradural placement around the spinal cord. The blades of the clip are $1.0 \mathrm{~mm}$ wide, $0.5 \mathrm{~mm}$ thick and $8 \mathrm{~mm}$ long. In making the injury, the two blades are placed on the anterior and posterior surfaces of the spinal cord and the cord is compressed between the two blades in the anterior-posterior direction of the cord for a distance of $1 \mathrm{~mm}$. Immediately after injury, human serum albumin $(1 \mathrm{ml} / \mathrm{kg})$ was injected intravenously as adjuvant therapy. After measurement of post-traumatic SCBF and EPs, rats were randomly assigned to one of two groups (five animals in each): $0.5 \mathrm{ml}$ of placebo or $0.5 \mathrm{ml}$ of $0.05 \mathrm{mg} / \mathrm{kg}$ nimodipine. The placebo or nimodipine was infused intrathecally for $30 \mathrm{~min}$ beginning $60 \mathrm{~min}$ after injury. SCBF was

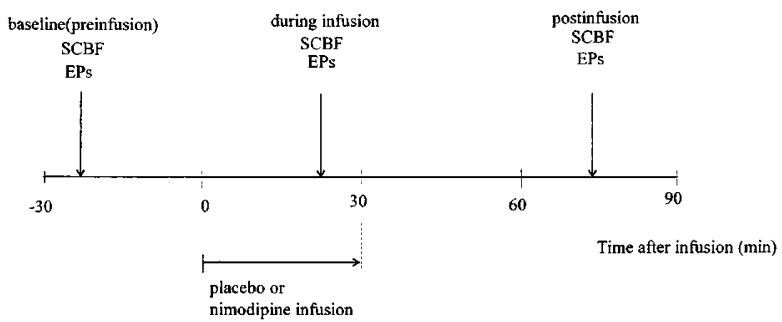

Figure 2 A schematic representation of the experimental protocol in the uninjured rats. SCBF was measured preinfusion (baseline), during infusion ( $22 \mathrm{~min}$ after start of infusion) and after infusion (72 min after start of infusion)

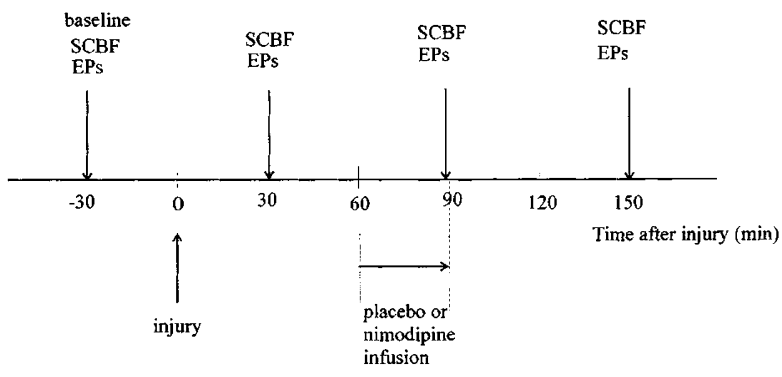

Figure 3 A schematic representation of the experimental protocol for the injured rats. SCBF was measured before injury (baseline), and then $30 \mathrm{~min}, 90 \mathrm{~min}$ (at the completion of infusion) and $150 \mathrm{~min}$ after injury ( $1 \mathrm{~h}$ after completion of infusion). Intrathecal infusion of nimodipine was started 60 min after injury

measured at 90 min (at the completion of infusion) and $150 \mathrm{~min}$ (1 h after completion of infusion) after injury (Figure 3). EPs were recorded after each measurement of SCBF, and immediately after injury.

\section{Statistical analysis}

In the text, the values given are mean \pm standard error of the mean. Statistical calculations were performed on a personal computer with Sigma Stat Version 1.0 (Jandel Scientific, San Rafael, CA). The physiological parameters and EPs were analyzed by paired t-test and SCBF values were analyzed by unpaired t-test. Comparison among the three groups at each time interval was performed by analysis of variance (ANOVA). Differences were considered significant at $P<0.05$.

\section{Results}

\section{Physiological parameters}

In the normal groups $\mathrm{pH}, \mathrm{PaCO}_{2}, \mathrm{PaO}_{2}$, hematocrit, and rectal temperature did not show any significant changes at any time of measurement (Table 1). However, MABP in the $0.2 \mathrm{mg} / \mathrm{kg}$ nimodipine group showed a significant decrease during infusion $(P=0.029)$ and post-infusion $(P=0.030)$. MABP began to decrease $9.8 \pm 1.2 \mathrm{~min}$ after the start of infusion and then decreased to $69.7 \pm 3.1 \%$ $(P<0.001)$ of baseline MABP $27.8 \pm 1.5 \mathrm{~min}$ after the onset of the infusion. This decrease in MABP remained until the end of experiment $(98.6 \pm 12.8$ min after start of infusion, $P=0.035$ ). In contrast, in the placebo and nimodipine $0.05 \mathrm{mg} / \mathrm{kg}$ groups, MABP showed no significant change during the experiment $(P>0.05)$.

In the spinal cord injury groups, $\mathrm{pH}$ and $\mathrm{PaO}_{2}$ showed no significant change during the experiment (Table 2). Although $\mathrm{PaCO}_{2}$ in the nimodipine $0.05 \mathrm{mg} /$ $\mathrm{kg}$ group significantly increased $150 \mathrm{~min}$ after injury 
$(P=0.0395)$, it was still within normal limits. In both the placebo and nimodipine groups, rectal temperature decreased significantly $90 \mathrm{~min}$ after injury $(P=0.035$ and $P=0.0002$, respectively), when the infusion was just finished. The heating lamp was not used during this phase because of the photosensitivity of nimodipine, and the heating blanket was not sufficient to maintain body temperature in the injured rat. The hematocrit decreased serially during the experiment in both groups, although the differences between baseline and subsequent time intervals reached significance only in the nimodipine groups (30 min after injury, $P=0.0002$; $90 \mathrm{~min}$ after injury; $P=0.0002$; and $150 \mathrm{~min}$ after injury, $P=0.0048)$. The reduction in hematocrit was likely due to the hemodiluting effect of albumin and the blood loss during the procedure, but it is not known why the differences were significant only in the nimodipine group.

MABP decreased significantly after injury in both injured groups (Table 2). In the placebo group there was no further decrease after the placebo infusion, while in the nimodipine group the MABP continued to decline after the infusion of nimodipine $(P=0.0142)$. However, $60 \mathrm{~min}$ after infusion of nimodipine, MABP recovered to the pre-infusion level post-injury $(P=0.0768)$, but did not return to the baseline.

Table 1 Physiological parameters determined before, during, after infusion in uninjured rats

\begin{tabular}{|c|c|c|c|c|}
\hline \multirow{2}{*}{$\begin{array}{l}\text { Dose } \\
(\mathrm{mg} / \mathrm{kg})\end{array}$} & \multirow[b]{2}{*}{ Parameter } & \multirow[b]{2}{*}{ Pre-infusion } & \multicolumn{2}{|c|}{ Time of determination } \\
\hline & & & During infusion & Post-infusion \\
\hline \multirow[t]{6}{*}{ Placebo } & $\mathrm{pH}$ & $7.36 \pm 0.01$ & $7.39 \pm 0.02$ & $7.39 \pm 0.01$ \\
\hline & $\mathrm{PaCO}_{2}(\mathrm{mmHg})$ & $40.2 \pm 1.6$ & $41.6 \pm 0.9$ & $40.8 \pm 1.6$ \\
\hline & $\mathrm{PaO}_{2}(\mathrm{mmHg})$ & $234.9 \pm 19.5$ & $256.8 \pm 12.7$ & $259.8 \pm 17.5$ \\
\hline & Hematocrit $(\%)$ & $37.1 \pm 1.9$ & $34.4 \pm 1.4$ & $33.6 \pm 3.3$ \\
\hline & Temperature $\left({ }^{\circ} \mathrm{C}\right)$ & $38.0 \pm 0.2$ & $38.3 \pm 0.2$ & $38.1 \pm 0.1$ \\
\hline & MABP (mmHg) & $103.6 \pm 5.5$ & $105.8 \pm 4.9$ & $111.2 \pm 4.2$ \\
\hline Nimodipine & $\mathrm{pH}$ & $7.38 \pm 0.01$ & $7.38 \pm 0.01$ & $7.39 \pm 0.01$ \\
\hline \multirow[t]{5}{*}{0.05} & $\mathrm{PaCO}_{2}(\mathrm{mmHg})$ & $37.7 \pm 0.9$ & $39.8 \pm 1.3$ & $39.6 \pm 1.2$ \\
\hline & $\mathrm{PaO}_{2}(\mathrm{mmHg})$ & $268.1 \pm 23.2$ & $282.4 \pm 18.9$ & $229.4 \pm 30.5$ \\
\hline & Hematocrit $(\%)$ & $33.0 \pm 2.2$ & $30.6 \pm 2.8$ & $29.8 \pm 2.5$ \\
\hline & Temperature $\left({ }^{\circ} \mathrm{C}\right)$ & $37.3 \pm 0.3$ & $36.9 \pm 0.3$ & $37.2 \pm 0.2$ \\
\hline & MABP (mmHg) & $93.4 \pm 6.2$ & $89.4 \pm 7.2$ & $90.0 \pm 5.3$ \\
\hline Nimodipine & $\mathrm{pH}$ & $7.38 \pm 0.01$ & $7.34 \pm 0.04$ & $7.39 \pm 0.01$ \\
\hline \multirow[t]{5}{*}{0.2} & $\mathrm{PaCO}_{2}(\mathrm{mmHg})$ & $37.2 \pm 1.9$ & $37.7 \pm 1.1$ & $39.4 \pm 1.4$ \\
\hline & $\mathrm{PaO}_{2}(\mathrm{mmHg})$ & $246.4 \pm 14.1$ & $230.9 \pm 28.4$ & $262.8 \pm 12.2$ \\
\hline & Hematocrit $(\%)$ & $35.4 \pm 2.0$ & $35.4 \pm 2.5$ & $35.2 \pm 2.3$ \\
\hline & Temperature $\left({ }^{\circ} \mathrm{C}\right)$ & $37.5 \pm 0.3$ & $37.2 \pm 0.2$ & $38.2 \pm 0.4$ \\
\hline & MABP (mmHg) & $115.6 \pm 2.7$ & $94.0 \pm 7.6^{*}$ & $101.0 \pm 5.9^{*}$ \\
\hline
\end{tabular}

Values are expressed as mean \pm SEM. Asterisk indicates a significant difference compared with baseline $(P<0.05)$. MABP: mean arterial blood pressure

Table 2 Physiological parameters in injured rats

\begin{tabular}{|c|c|c|c|c|c|}
\hline \multirow[b]{2}{*}{ Group } & \multirow[b]{2}{*}{ Parameter } & \multicolumn{4}{|c|}{ Time after injury } \\
\hline & & Baseline & $30 \mathrm{~min}$ & $60 \min$ & $150 \mathrm{~min}$ \\
\hline \multirow[t]{6}{*}{ Placebo } & $\mathrm{pH}$ & $7.41 \pm 0.01$ & $7.42 \pm 0.02$ & $7.43 \pm 0.01$ & $7.41 \pm 0.02$ \\
\hline & $\mathrm{PaCO}_{2}(\mathrm{mmHg})$ & $39.3 \pm 2.0$ & $38.4 \pm 1.6$ & $39.5 \pm 0.4$ & $40.9 \pm 1.5$ \\
\hline & $\mathrm{PaO}_{2}(\mathrm{mmHg})$ & $234.7 \pm 2.2$ & $223.3 \pm 28.3$ & $241.8 \pm 15.2$ & $204.3 \pm 24.8$ \\
\hline & Hematocrit $(\%)$ & $30.0 \pm 4.3$ & $26.8 \pm 4.4$ & $24.2 \pm 1.2$ & $21.4 \pm 2.6$ \\
\hline & Temperature $\left({ }^{\circ} \mathrm{C}\right)$ & $37.6 \pm 0.4$ & $37.6 \pm 0.4$ & $36.3 \pm 0.4^{*}$ & $37.1 \pm 0.2$ \\
\hline & MABP (mmHg) & $95.0 \pm 3.0$ & $69.8 \pm 3.6^{*}$ & $70.0 \pm 2.3^{*}$ & $74.4 \pm 6.1^{*}$ \\
\hline & $\mathrm{pH}$ & $7.39 \pm 0.01$ & $7.40 \pm 0.01$ & $7.39 \pm 0.02$ & $7.39 \pm 0.01$ \\
\hline \multirow[t]{5}{*}{$(0.05 \mathrm{mg} / \mathrm{kg})$} & $\mathrm{PaCO}_{2}(\mathrm{mmHg})$ & $37.8 \pm 1.2$ & $38.1 \pm 1.6$ & $41.1 \pm 1.9$ & $42.2 \pm 0.5^{*}$ \\
\hline & $\mathrm{PaO}_{2}(\mathrm{mmHg})$ & $242.6 \pm 13.5$ & $222.6 \pm 10.4$ & $241.1 \pm 14.9$ & $225.91 \pm 4.7$ \\
\hline & Hematocrit $(\%)$ & $37.2 \pm 1.7$ & $32.0 \pm 2.1^{*}$ & $30.8 \pm 1.5^{*}$ & $26.4 \pm 1.6^{*}$ \\
\hline & Temperature $\left({ }^{\circ} \mathrm{C}\right)$ & $38.0 \pm 0.2$ & $38.1 \pm 0.1$ & $36.4 \pm 0.1^{*}$ & $37.4 \pm 0.3$ \\
\hline & MABP (mmHg) & $117.4 \pm 4.1$ & $87.0 \pm 5.3^{*}$ & $66.8 \pm 1.2^{*}$ & $73.0 \pm 2.3 *$ \\
\hline
\end{tabular}

Values are expressed as mean \pm SEM. Asterisk indicates a significant difference compared with baseline $(P<0.05)$. MABP: mean arterial blood pressure 
$S C B F$

In the uninjured groups the baseline SCBF values in the placebo group, the nimodipine $0.05 \mathrm{mg} / \mathrm{kg}$ group, and the nimodipine $0.2 \mathrm{mg} / \mathrm{kg}$ group were $57.8 \pm 5.0$, $52.0 \pm 5.3$, and $57.1 \pm 7.7 \mathrm{ml} / 100 \mathrm{~g} / \mathrm{min}$, respectively (Figure 4). There were no significant changes during placebo or nimodipine infusion $(P=0.103, P=0.132$, and $P=0.434$, respectively), or after infusion ( $P=0.076, P=0.543$, and $P=0.800$, respectively).

In the injured groups, the decline in SCBF was not significant $30 \mathrm{~min}$ after injury in the placebo group $(P=0.094)$ or in the nimodipine $0.05 \mathrm{mg} / \mathrm{kg}$ group $(P=0.082)$, but the decline was significant during the infusion $90 \mathrm{~min}$ after injury in both the placebo to $(65.3 \pm 9.0 \%$ of baseline, $P=0.0034)$ and nimodipine groups (to $54.5 \pm 6.9 \%$ of baseline, $P=0.0003$ ) (Figure $5)$. One hour after completion of the infusion (150 $\mathrm{min}$ after injury) SCBF remained low without evidence of recovery in either the placebo or nimodipine groups $(70.7 \pm 7.5 \%$ of baseline, $P=0.0165$ and $58.7 \pm 3.6 \%$ of baseline, $P<0.0001$, respectively).

\section{EPS}

(1) SSEP in the uninjured groups Although the latency of both P13 and N18 in the nimodipine $0.05 \mathrm{mg} / \mathrm{kg}$ and $0.2 \mathrm{mg} / \mathrm{kg}$ groups showed no significant change during infusion or after infusion $(P>0.05)$, there was a significant increase in the latency of P13 during infusion and after infusion $(P=0.0348$ and $P=0.0090$, respectively) and of N18 after infusion $(P=0.0178)$ in the placebo group (Figure 6). However, there was no significant difference among the three groups at any time of recording $(P>0.05)$. Similarly, the amplitude did not show a significant change in any group during infusion or after infusion $(P>0.05)$, although there was a large variability between individual animals as shown by the large standard errors.

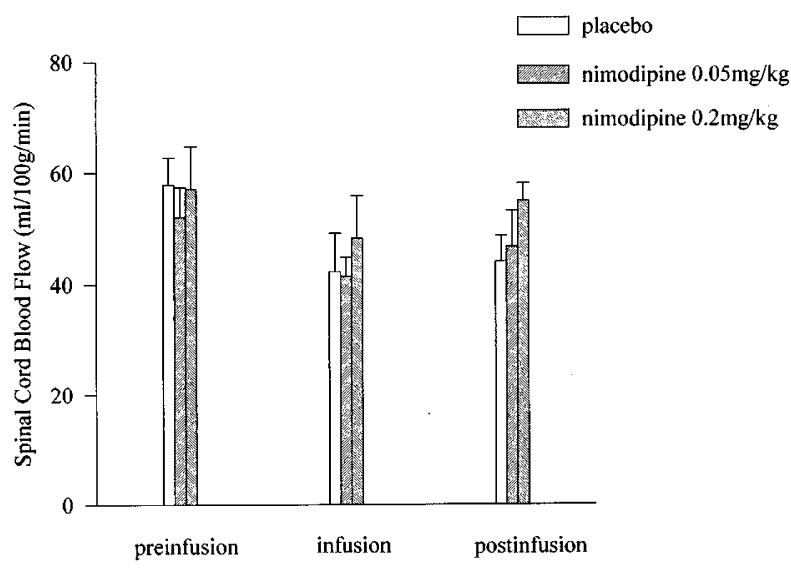

Figure $4 \mathrm{SCBF}($ mean $\pm \mathrm{SEM})$ recorded at $\mathrm{T} 1$ in the uninjured groups. SCBF showed no significant change during infusion and post-infusion in each group
(2) CEP in the uninjured groups The latency of P14 in the nimodipine $0.2 \mathrm{mg} / \mathrm{kg}$ group showed a very small but significant increase during infusion $(P=0.0330)$, but recovered to pre-infusion level after completion of the infusion $(P=0.3739)$ (Figure 7$)$. The amplitude of $\mathrm{N} 9$ and $\mathrm{P} 14$ in the nimodipine $0.2 \mathrm{mg} / \mathrm{kg}$ group decreased significantly during $(P=0.0263$ and $P=0.0407$, respectively) and after $(P=0.0139$ and $P=0.0146$, respectively) infusion, and the amplitude of P14 in the placebo and the nimodipine $0.05 \mathrm{mg} / \mathrm{kg}$ groups decreased after infusion $(P=0.0375$ and $P=0.0004$, respectively). However, there was no significant difference among the three groups at any time of recording.

(3) SSEP in the injured groups The SSEPs disappeared immediately after injury in all animals, and then reappeared in five animals (two in the placebo group and three in the nimodipine $0.05 \mathrm{mg} / \mathrm{kg}$ group) $30 \mathrm{~min}$ after injury, although the amplitudes were decreased and the latencies were increased significantly $(P<0.05)$ (Figure 8). After completion of the infusion of placebo or nimodipine ( $90 \mathrm{~min}$ after injury), only one rat in each group retained an SSEP. At $150 \mathrm{~min}$ after injury (60 min after completion of the infusion) one animal in the placebo group and three animals in the nimodipine group showed SSEPs (SSEPs in two animals in the nimodipine group reappeared). The

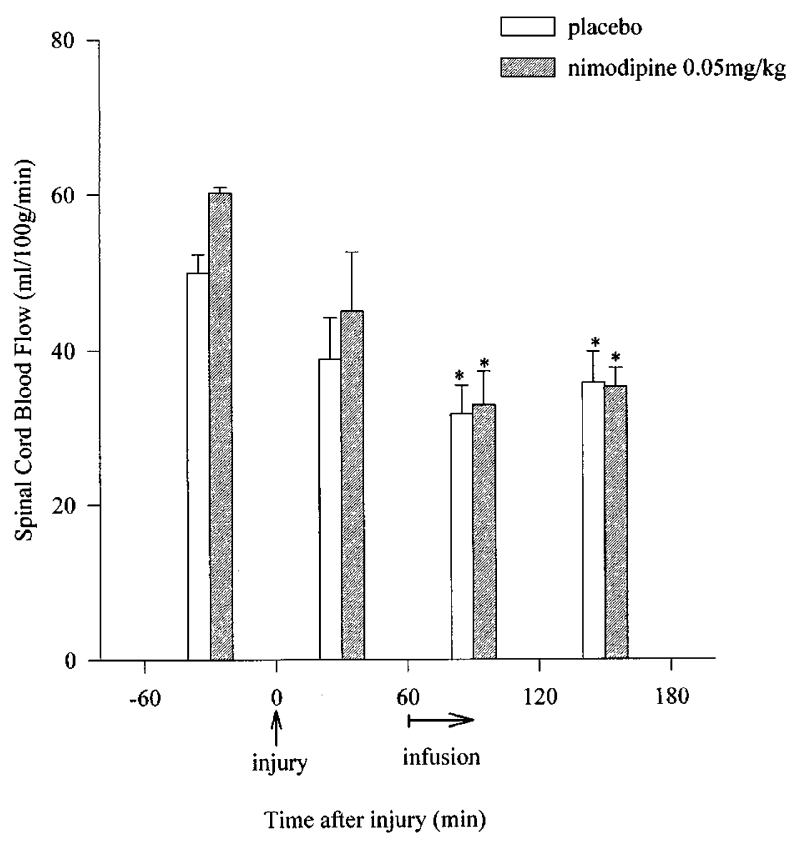

Figure $5 \mathrm{SCBF}$ (mean \pm SEM) recorded in the injured rats. SCBF decreased significantly $90 \mathrm{~min}$ after injury to $54.5 \pm 6.9 \%$ of baseline in the nimodipine group and $65.3 \pm 9.0 \%$ in the placebo group and showed no recovery $150 \mathrm{~min}$ after injury. There was no significant difference between the two groups. Asterisk indicates a significant difference from the baseline in each group 

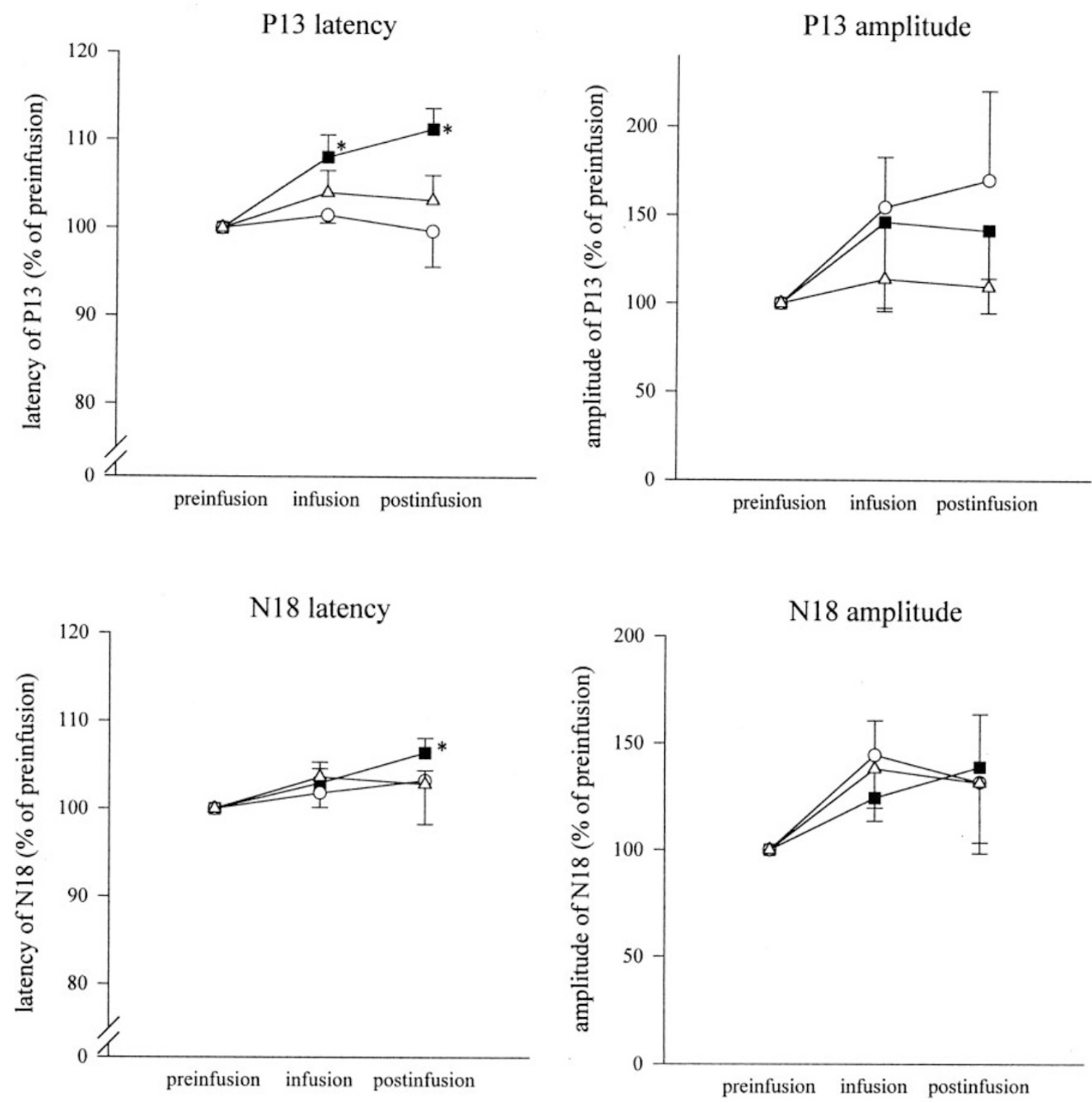

Figure 6 SSEP in the uninjured groups. The latency of both P13 and N18 in the nimodipine $0.05 \mathrm{mg} / \mathrm{kg}$ and $0.2 \mathrm{mg} / \mathrm{kg}$ groups showed no significant change from baseline during infusion and after infusion. In the placebo group, the latency of P13 during infusion and after infusion and N18 after infusion increased significantly. However, there was no significant difference in the latency change among the three groups at any time of recording. The amplitude did not show a significant change in any group during infusion or after infusion, although there was a large inter-individual variability. The square symbol indicates the placebo group, the circle indicates the nimodipine $0.05 \mathrm{mg} / \mathrm{kg}$ group, and the triangle indicates the nimodipine $0.2 \mathrm{mg} / \mathrm{kg}$ group. The error bar indicates SEM and the asterisks indicate a significant difference from the baseline in each group

amplitude of the SSEP decreased significantly immediately after injury and showed no recovery thereafter in either group $(P<0.0001)$ (Figure 8).

(4) CEP in the injured groups In the placebo group, the CEPs in three rats disappeared immediately after injury. In one of these rats the CEP reappeared at $30 \mathrm{~min}$, persisted by $90 \mathrm{~min}$, but disappeared again $150 \mathrm{~min}$ after injury. In the nimodipine $0.05 \mathrm{mg} / \mathrm{kg}$ group, the CEPs of four rats remained immediately after injury, although the amplitude decreased significantly $(P<0.0001)$. In one of these rats the CEP disappeared $90 \mathrm{~min}$ after injury and did not reappear after that. The amplitude of the CEP decreased significantly immediately after injury and showed no recovery after that $(P<0.001)$ (Figure 8). There was no significant difference in the amplitude changes between the two groups at any time $(P>0.05)$. 

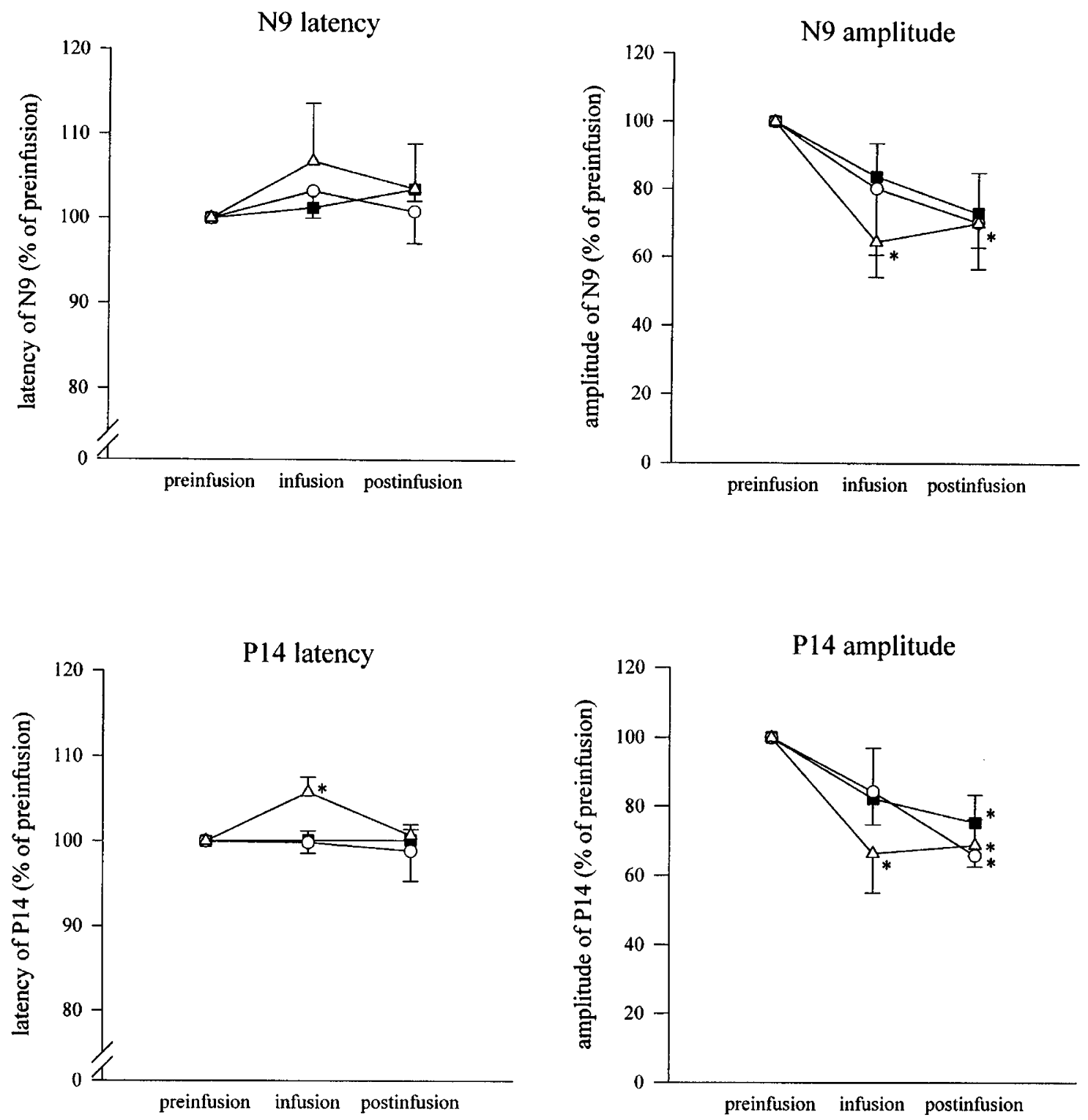

Figure $7 \mathrm{CEP}$ in the uninjured groups. The latency of P14 in the nimodipine $0.2 \mathrm{mg} / \mathrm{kg}$ group showed a significant increase during infusion, although it then recovered to the pre-infusion level. The amplitude of N9 and P14 in the nimodipine $0.2 \mathrm{mg} / \mathrm{kg}$ group decreased significantly during and after infusion. The amplitude of P14 in the placebo and nimodipine $0.05 \mathrm{mg} / \mathrm{kg}$ groups decreased after infusion. There was no significant difference in the change among the three groups at any time of recording. The square symbol indicates the placebo group, the circle indicates the nimodipine $0.05 \mathrm{mg} / \mathrm{kg}$ group, and the triangle indicates the nimodipine $0.2 \mathrm{mg} / \mathrm{kg}$ group. The error bar indicates SEM and the asterisks indicate a significant difference from the baseline in each group

\section{Discussion}

There have been many studies of the effects on the normal spinal cord of the intrathecal administration of various drugs. ${ }^{21}$ However, there have been few reports of the effects of intrathecal drugs on SCBF measured by the hydrogen clearance technique. This method requires a small opening in the dura for the insertion of an electrode into the spinal cord, and thus it is possible that there may be leakage of CSF and drug through this opening. The laser doppler method of measuring SCBF does not require a dural opening and has been used in some studies of intrathecal drug administration, but this method has the major shortcoming of being unable to provide absolute blood flow values. ${ }^{20}$ Matsumiya et al administered morphine into the spinal 

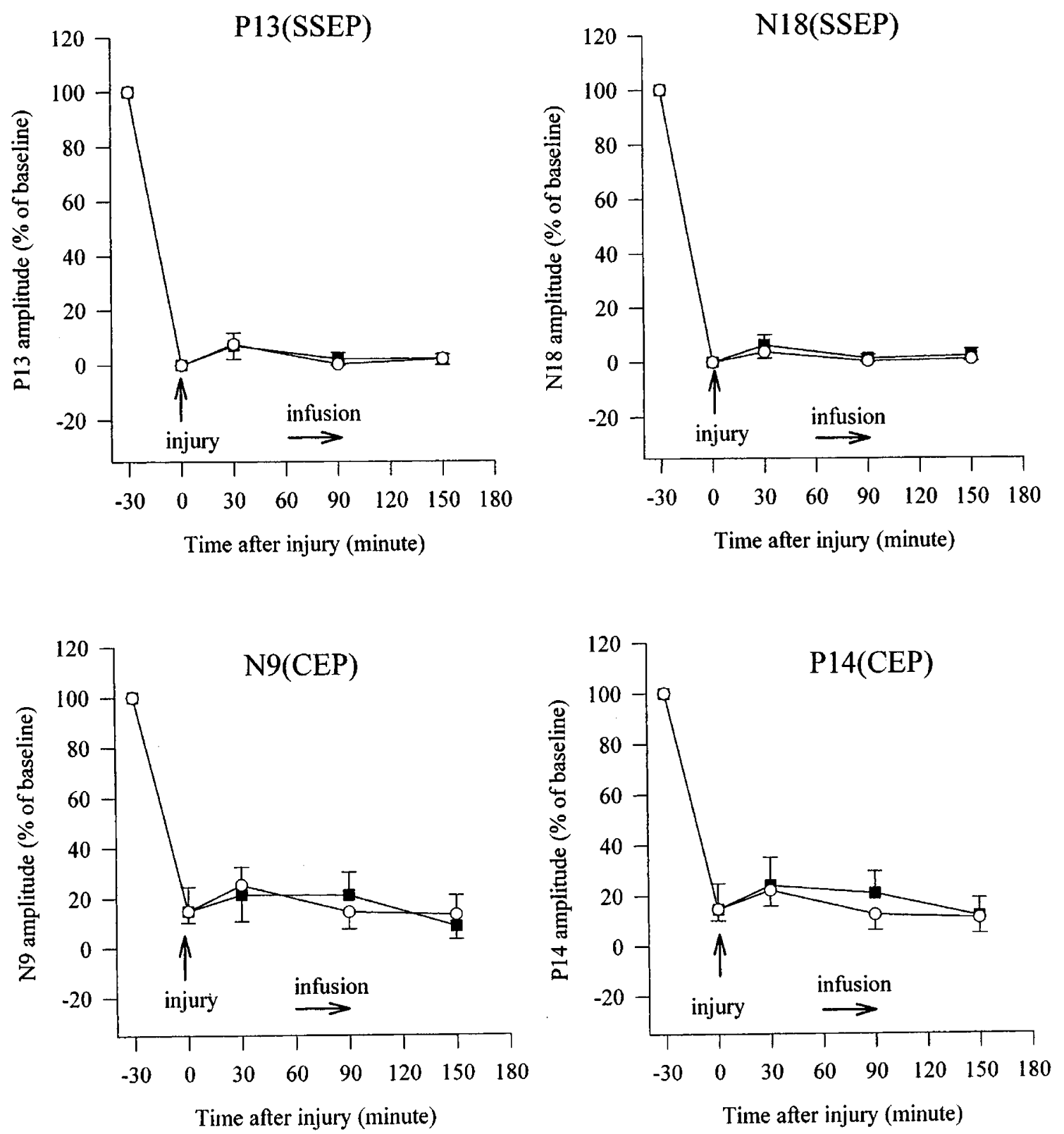

Figure 8 Amplitude of EPs in the injured groups. Both the SSEP and CEP showed a significant decrease in amplitude after injury without any subsequent recovery. There was no significant difference between the two groups. The closed square symbol indicates the placebo group and the open circle indicates the nimodipine $0.05 \mathrm{mg} / \mathrm{kg}$ group

subarachnoid space of dogs and measured SCBF by the $\mathrm{H}_{2}$ clearance method. ${ }^{22}$ They used a platinum electrode, $100 \mathrm{~mm}$ diameter, placed $1 \mathrm{~cm}$ caudal to the intrathecal catheter and at a depth of $3-5 \mathrm{~mm}$ from the surface of the spinal cord. However, there was no information given about CSF or drug leakage through the dural opening.

Intrathecal drugs may exert local actions on the spinal cord, or, especially in the case of lipophilic drugs, may act systemically following absorption into the circulation of the cord. Also, intrathecal drugs may act supraspinally, following ascent of the drug through the CSF circulation. ${ }^{21,26}$ Bernard et al showed that lipophilic drugs were easily absorbed into the spinal cord capillaries, and that these drugs were also lost from the spinal CSF by crossing the arachnoid-dural membranes into the epidural space, with greater permeability than hydrophillic drugs. ${ }^{27}$ In the present study, there would have been an additional loss of some of the drug due to leakage through the dural 
holes made for the electrodes. Also, we infused a relatively larger volume of nimodipine or placebo $(0.5 \mathrm{ml})$ into the rat subarachnoid space than the $1 \mathrm{ml}$ which Matsumiya et al infused into the canine subarachnoid space. ${ }^{22}$ Smaller volumes were not used because we thought that a small volume of nimodipine would not have remained in contact with the spinal cord surface for a sufficiently long time to counteract the effects of trauma.

In our previous experiment, ${ }^{28}$ intravenous nimodipine at a dose of $0.05 \mathrm{mg} / \mathrm{kg}$ produced a $40 \%$ increase in SCBF and a $25 \%$ decrease in MABP in uninjured rats, while higher doses induced a marked decrease in MABP with little increase in SCBF. In the present experiment, intrathecal nimodipine at a dose of $0.05 \mathrm{mg} / \mathrm{kg}$ caused neither a significant increase in SCBF nor a significant decrease in MABP. Intrathecal nimodipine at a dose of $0.2 \mathrm{mg} / \mathrm{kg}$ failed to increase $\mathrm{SCBF}$, but did cause a significant reduction in MABP, which suggests that some of the drug entered the systemic circulation to cause this depressor effect. In the present experiment, intrathecal administration of the smaller dose did not cause hypotension, perhaps because systemic leakage was insufficient to induce a depressor effect. In one of our previous experiments, intravenous nimodipine and dextran improved the SSEP and the motor evoked potential following SCI, but after cessation of these treatments axonal function declined again. ${ }^{7}$ In another study, neither intravenous nimodipine nor methylprednisolone produced any recovery in the EPs. ${ }^{15}$

In the uninjured animals intrathecal nimodipine did not produce any major effects on the EPs. The latency of the SSEP in the placebo group showed a significant increase after infusion, although the amplitudes of the SSEP in the three groups (placebo, $0.05 \mathrm{mg} / \mathrm{kg}$ nimodipine and $0.2 \mathrm{mg} / \mathrm{kg}$ nimodipine) showed neither a significant change compared with the preinfusion values nor was there a significant difference among these groups. The amplitude of the CEP (but not the SSEP) decreased significantly in all groups by the end of experiment, perhaps due to a toxic effect of one or more of the ingredients in the vehicle. It has been noted that the SSEP amplitude may remain unchanged or may increase despite pathologic evidence of spinal cord trauma. ${ }^{24}$ Thus, the CEP may be a more reliable index of axonal function.

In the injured animals, we assessed only the lower dose of intrathecal nimodipine because of the systemic hypotension caused by the higher dose in normal animals (Table 1). To counteract the post-traumatic hypotension caused by the spinal cord injury, both groups of injured animals received a bolus injection of $1 \mathrm{ml}$ of albumin. It was hoped that intrathecal administration of nimodipine would obviate or minimize the need for post-traumatic adjuvant therapy to counteract hypotension. Unfortunately, there was no beneficial effect of intrathecal nimodipine on either post-traumatic spinal cord ischemia or axonal dysfunction as measured by the EPs. After injury, MABP decreased significantly in both groups, and then the nimodipine group showed a further decrease in MABP. Thus, the intrathecal route of nimodipine administration did not eliminate the side effect of hypotension.

With the dissecting microscope we observed significant swelling of the injured spinal cord beginning about $30 \mathrm{~min}$ after injury. The swelling caused a marked reduction in the subarachnoid space at the injury site. In our previous studies of intravenous nimodipine ${ }^{7,9,10,15}$ the dura was opened widely to facilitate measurement of SCBF with the $\mathrm{H}_{2}$ electrode technique. In the present study, the reduction of the subarachnoid space by the edematous spinal cord may have disturbed the subarachnoid circulation and subsequent penetration and distribution of nimodipine into the injured spinal cord.

Blood flow is affected by changes in $\mathrm{PaCO}_{2}$ and body temperature. ${ }^{29,30}$ In the present study these parameters were still within normal limits in spite of minor differences compared with the baseline. However, the hematocrit decreased significantly after injury in the nimodipine group probably due to hypovolemia and the continuous infusion of albumin, although there should have been no significant difference in blood loss or hydration between the nimodipine and the placebo groups. The hematocrit is an important factor in determining blood viscosity, and blood flow increases in proportion to a decrease in viscosity. ${ }^{7}$ However, post-traumatic blood flow is markedly dependent on MABP because of the absence of autoregulation at the injury site. ${ }^{31}$ At the injury site non-rheological factors such as vasospasm can also change the blood flow..$^{2,3,7,32}$ In the present study even if intrathecal nimodipine had reduced vasospasm, it may not have been able to overcome the decrease in blood flow due to the lowering of the blood pressure. It is probably necessary to maintain blood pressure at a normal level to obtain a beneficial effect with nimodipine after spinal cord injury. ${ }^{11,17}$ Failure to improve post-traumatic SCBF and axonal function in the present study suggests that even intrathecal nimodipine therapy for spinal cord injury requires vigorous adjuvant therapy to restore post-traumatic normotension.

In the present study, we administered nimodipine intrathecally for only $30 \mathrm{~min}$. It is possible that longer term administration of nimodipine and later measurement of SCBF and EPs may have shown better results. More time may have been required to achieve better penetration of nimodipine into the injured spinal cord.

\section{Conclusions}

Intrathecal nimodipine did not increase SCBF in the normal rat, though $0.2 \mathrm{mg} / \mathrm{kg}$ nimodipine induced a significant decrease in MABP. There was a significant decrease in the amplitude of the CEP. Intrathecal nimodipine in rats with acute spinal cord injury did not 
produce any beneficial effects on post-traumatic SCBF or axonal function, but caused a further decline in MABP.

\section{Acknowledgements}

The authors acknowledge the technical assistance of Mrs Rita van Bendegem, Ms Linda Lee and Mr Jim Loukides. H Imamura was supported by the Rick Hansen Man in Motion Legacy Fund and the Network for Neural Recovery and Regeneration of the Canadian Networks of Centres of Excellence. Operating funds for this project were provided by the Canadian Paraplegic Association, Samuel Lunenfeld Research Foundation and the Medical Research Council of Canada.

\section{References}

1 Faden AI. Experimental neurobiology of central nervous system trauma. Crit Rev Neurobiology 1993; 7: 175-186.

2 Tator CH. Ischemia as a secondary neural injury. In: Salzman SK and Faden AI (eds). The Neurobiology of Central Nervous System Trauma. Oxford University Press: NY, 1994, pp 209-215.

3 Tator $\mathrm{CH}$, Fehlings MG. Review of the secondary injury theory of acute spinal cord trauma with emphasis on vascular mechanisms. J Neurosurg 1991; 75: 15-26.

4 Black P et al. Experimental spinal cord injury: effect of a calcium channel antagonist (nicardipine). Neurosurgery 1988; 22: 61-66.

5 Ceylan $\mathrm{S}$ et al. Treatment of acute spinal cord injuries: comparison of thyrotropin-releasing hormone and nimodipine. Res Exp Med 1992; 192: 23-33.

6 Faden AI, Thomas PJ, Smith MT. Evaluation of calcium channel antagonist nimodipine in experimental spinal cord ischemia. $J$ Neurosurg 1984; 60: 796 - 799.

7 Fehlings MG, Tator CH, Linden RD. The effect of nimodipine and dextran on axonal function and blood flow following experimental spinal cord injury. J Neurosurg 1989; 71: 403-416.

8 Ford RW, Malm DN. Failure of nimodipine to reverse acute experimental spinal cord injury. Cent Nerv Syst Trauma 1985; 2: $9-17$.

9 Guha A, Tator CH, Piper I. Effect of a calcium channel blocker on post-traumatic spinal cord blood flow. J Neurosurg 1987; 66: $423-430$.

10 Guha A et al. Improvement in post-traumatic spinal cord blood flow with a combination of a calcium channel blocker and avasopressor. J Trauma 1989; 29: 1440 - 1447.

11 Haghighi SS et al. Evaluation of the calcium channel antagonist nimodipine after experimental spinal cord injury. Surg Neurol 1933; 39: $403-408$.

12 Hithcon PW et al. Nicardipine after spinal cord compression in the lamb. Surg Neurol 1989; 31: 101-110.

13 Holtz A, Nystròm B, Gerdin B. Spinal cord injury in rats: inability of nimodipine or anti-neutrophil serum to improve spinal cord blood flow or neurologic status. Acta Neurol Scand 1989; 79: $460-467$.
14 Pointillart V et al. Effect of nimodipine on post-traumatic spinal cord ischemia in baboons. $J$ Neurotrauma 1993; 10: $201-213$.

15 Ross IB, Tator CH. Spinal cord blood flow and evoked potential responses after treatment with nimodipine or methylprednisolone in spinal cord-injured rats. Neurosurgery 1993; 33: 470-477.

16 Voldby B et al. Reversal of cerebral arterial spasm by intrathecal administration of a calcium antagonist (nimodipine). An experimental study. Acta Neurochir 1984; 70: 243 - 254.

17 Haghighi SS, Chehrazi BB, Wagner Jr FC. Effect of nimodipineassociated hypotension on recovery from acute spinal cord injury in cats. Surg Neurol 1988; 29: 293-297.

18 Naftchi NE, Demeny M, DeCrescito V. Biogenic amine concentrations in traumatized spinal cords of cats. Effects of drug therapy. J Neurosurg 1974; 40: 52-57.

19 Osterholm JL, Mathews GJ. Altered norepinephrine metabolism following experimental spinal cord injury. Part 1: Relationship to hemorrhagic necrosis and post-wounding neurological deficits. $J$ Neurosurg 1972; 36: 386-394.

20 Kristeinsen JD, Karlsten R, Gordh T. Laser-doppler evaluation of spinal cord blood flow after intrathecal administration of an N-methyl-D-aspartate antagonist in rats. Anesth Analg 1994; 78: $925-931$.

21 Kroin JS. Intrathecal drug administration, present use and future trends. Clin Pharmacokinet 1992; 22: $319-326$.

22 Matsumiya N, Dohi S. Effect of intravenous or subarachnoid morphine on cerebral and spinal cord hemodynamics and antagonism with naloxone in dogs. Anesthesiology 1983; 59: $175-181$.

23 Piper I, Guha A, Tator CH, Gentles W. A microcomputer for online collection of blood flow and related physiological data. Comput Biol Med 1987; 17: 279-299.

24 Hulbert RJ, Koyanagi I, Tator CH. Sensory evoked potential for selective monitoring of the rat spinal cord: a cerebellar evoked potential to assess ventral cord integrity. J Neurotrauma 1993; 10: $181-200$.

25 Rivlin AS, Tator $\mathrm{CH}$. Effect of duration of acute spinal cord compression in a new acute cord injury model in the rat. Surg Neurol 1978; 10: $39-43$.

26 Crosby G. Local spinal cord blood flow and glucose utilization during spinal anesthesia with bupivacaine in conscious rats. Anesthesiology 1985; 63: 55-60

27 Bernard CM, Hill HF. Morphine and alfentanil permeability through the spinal dura, arachnoid, and pia mater of dogs and monkeys. Anesthesiology 1990; 73: 1214-1219.

28 Guha A, Tator CH, Piper I. Increase in rat spinal cord blood flow with the calcium channel blocker, nimodipine. J Neurosurg 1985; 63: $250-259$.

29 Davis DG. Temperature and cerebral blood flow regulation in the freshwater turtle, pseudemys scripta. Respir Physiol 1994; 95: $329-335$.

30 Hindman BJ et al. Brain blood flow and metabolism do not decrease at stable brain temperature during cardiopulmonary bypass in rabbits. Anesthesiology 1992; 77: 342-350.

31 Guha A, Tator CH, Rochon J. Spinal cord blood flow and systemic blood pressure after experimental spinal cord injury in rats. Stroke 1989; 20: $372-377$.

32 Koyanagi I, Tator CH, Lea PJ. Three-dimensional analysis of the vascular system in the rat spinal cord with scanning electron microscopy of vascular corrosion casts. Part 2: acute spinal cord injury. Neurosurgery 1993; 33: 285-292. 